\title{
UNEVENTFUL EXTRADURAL ANALGESIA AFTER UNRECOGNIZED DURAL PERFORATION
}

\section{SERGIo GREGORETTI}

DURAL PUNCTURE by an extradural catheter threaded through a needle correctly positioned in the extradural space is a well known albeit rare, complication of continuous extradural analgesia. ${ }^{1-3}$ The subarachnoid location of the catheter, if not detected by aspiration of cerebrospinal fluid or after a test of local anaesthetic, is usually recognized when an unduly high ${ }^{4}$ or total spinal block results from the first injection of local anaesthetic. A case is reported here of a dura perforation recognized late during an apparently normal extradural block.

\section{CAse Report}

A 68-year-old man (weight $67 \mathrm{~kg}$, height $170 \mathrm{~cm}$ ) was scheduled for a left femoral popliteal by-pass graft for chronic arterial insufficiency. His medical history was unremarkable apart from inild hypertension treated with methyldopa and silorthalidone; physical examination and laboratory findings were normal. A 16-gauge Tuohy needle was inserted between L2-L3 with the patient in left lateral position and the epidural space identified using the loss-of-resistance test with air. A Portex epidural catheter was inserted $4 \mathrm{~cm}$ into the epidural space with some difficulty. As blood was aspirated persistently, the catheter was removed and a second epidural puncture was made between L1-L2. This time the catheter was easily inserted $3 \mathrm{~cm}$ into the space and no paresthesiae were elicited. When careful aspiration failed to produce fluid, a Millipore filter was attached to the hub of the catheter and $15 \mathrm{ml}$ of bupivacaine 0.5 per cent were injected with the patient in left lateral position. During the following 15 minutes pin-prick analgesia tested only on the left side rose to $\mathrm{T} 8$ and the blood pressure decreased from 160 torr $(21.3 \mathrm{kPa})$ to 140 torr $(18.6 \mathrm{kPa})$ after infusion of one litre of Hartmann's solution. Two hours later a reinforcement dose of $10 \mathrm{ml}$ of 0.5 per cent bupivacaine was

Sergio Gregoretti, M.D.. Department of Anaesthesia, Royal Victoria Hospital, 687 Pine A venue West, Montreal, Que., H3A 1 A1.

Present address: Dept. of Anaesthesia, Ospedale Maggiore, Trieste, Italy. injected over one minute without previous aspiration, aiming at a more localized and intense block. After a few minutes the patient complained that some fluid was dripping onto his shoulder. On examination fluid was seen to drip from the catheter where the Millipore filter had become partially disconnected. On removing the filter entirely, $2 \mathrm{ml}$ of clear fluid were aspirated from the catheter with considerable ease, using a $2 \mathrm{~m} /$ syringe. At this time the level of analgesia was found to extend symmetrically to T6 and this did not change during the following 30 minutes. Systolic blood pressure remained stable at 140 torr $(18.6 \mathrm{kPa})$. At this time, about 40 minutes after the reinforcing dose, another attempt was made to aspirate fluid from the catheter. Again, $2 \mathrm{ml}$ of clear fluid were easily obtained. The chemical properties of this fluid were analyzed with urine* and blood glucose t test strips.

$\mathrm{A} \mathrm{pH}$ of 7 and the presence of glucose $45-90 \mathrm{mg}$ per cent on the test strips suggested that cerebrospinal fluid had been obtained from the catheter. ${ }^{5}$ Bupivacaine tested with the same strips was shown to have a pH of 5 and to contain no glu. cose.

At the end of the operation, two hours and iwenty minutes after the reinforcing dose, the level of analgesia extended to T10 on the left side and to $\mathrm{Ll}$ on the right. Lower limb motor block was almost complete on both sides.

Location of the catheter was determined by $X$-ray because of the confusing clinical features. Three $\mathrm{ml}$ of iocarmic acid (Dimer-X) were injected through the catheter with the patient supine and a radiograph, taken at the bedside with a portable machine, showed contrast medium spreading into the subarachnoid space (Figure 1). A second radiograph taken a few minutes later, after slowly injecting $6 \mathrm{ml}$ of diluted contrast medium, revealed some of it in the epidural space as well. (Figure 2). The catheter was then removed.

The patient was observed for five days and made a complete recovery with no complaints of headache or symptoms or meningeal irritation.

*BM Test 3, Bocringher-Mannheim.

$\dagger$ Ames Destrosix. 

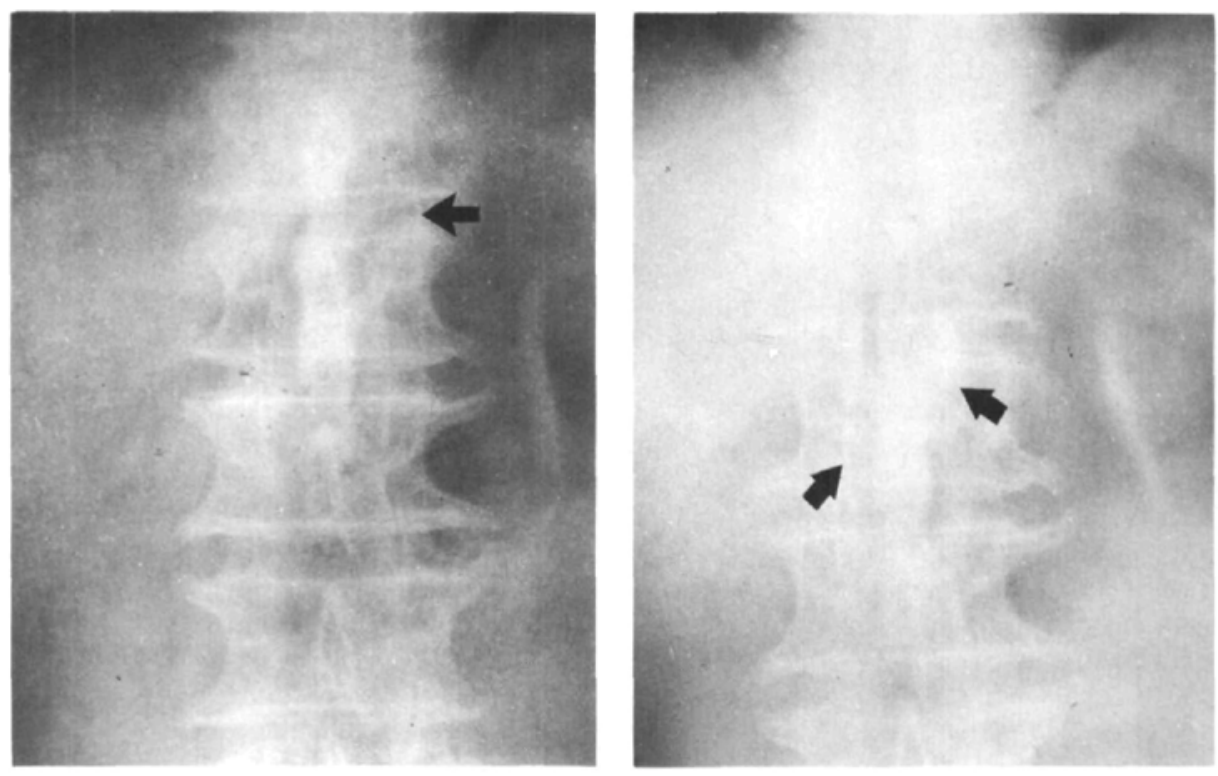

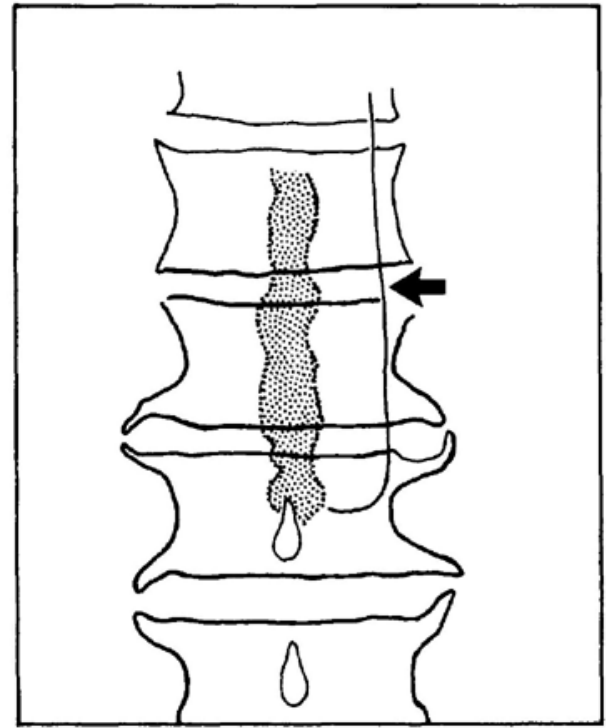

Figure 1 After injection of $3 \mathrm{ml}$ of contrast medium, the dye can be seen in the subarachnoid space at the level of $\mathrm{T} 12$ and $\mathrm{L} 1$. The catheter can also be seen filled with contrast (arrow).

\section{Discussion}

The clinical picture of this patient suggests that he initially had an extradural block. There was no evidence of cerebrospinal fluid on aspiration from

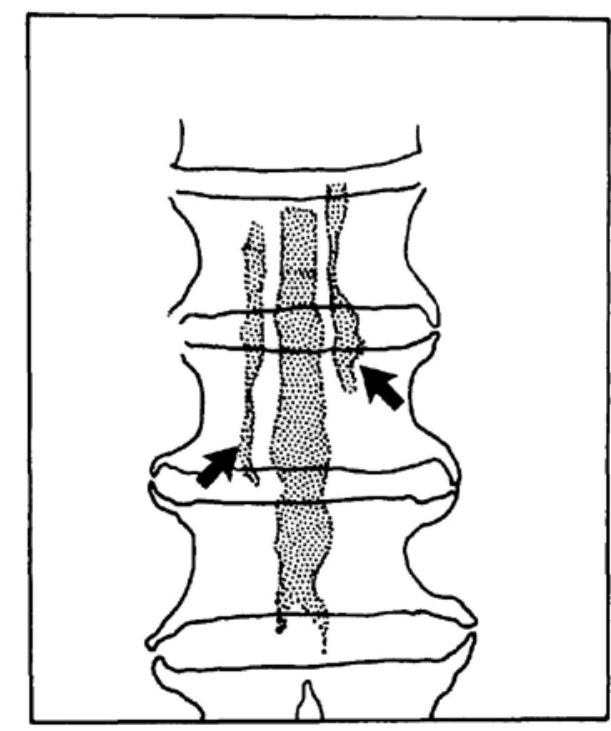

FIGURE 2 After injection of diluted contrast medium, some dye can be seen in the extradural space (arrows).

the catheter and despite the large amount of bupivacaine injected $(75 \mathrm{mg})$ the level of analgesia after 15 minutes did not rise above T8.

Two hours later, after the reinforcing dose of $10 \mathrm{ml}$ of 0.5 per cent bupivacaine, fuid with the 
chemical properties of cerebrospinal fluid was easily aspirated from the catheter on two occasions, 40 minutes apart. $X$-rays confirmed the subarachnoid location of the catheter. A possible explanation for the normal extradural block and the subsequent discovery of the catheter in the subarachnoid space is that the catheter was initially positioned correctly in the epidural space, but later passed through the dura. Although there was no evidence of perforation of the dura when either the needle or the catheter were first inserted, the perforation probably occurred at that time. It is difficult to understand how a thin catheter, softened at body temperature, could later perforate a tough membrane like the dura.

The writer has been able to find only one case in the literature of probable late entry of an extradural catheter in which a total spinal block followed a second dose of $7 \mathrm{ml}$ of 0.5 per cent bupivacaine given two hours and 40 minutes after an uneventful epidural block. ${ }^{6}$ In contrast, in the present case the level of analgesia did not rise above $T 6$ despite a second dose of $10 \mathrm{ml}$ of 0.5 per cent bupivacaine.

The most likely explanation of such an uneventful course is that the full reinforcing dose of bupivacaine did not reach the subarachnoid space. Whereas the first $X$-ray showed the contrast medium only in the subarachnoid space, the second showed some contrast medium in the extradural space as well. As the Portex catheter has two lateral holes on the tip $8 \mathrm{~mm}$ apart, it is possible that the distal hole was intradural and the proximal one extradural.

It has been calculated that, with the patient supine, 75 per cent of an injected volume will pass through the distal hole of such a catheter with a forceful injection and 50 per cent with a slow injection. ${ }^{7}$ The first injection of contrast medium was given very quickly and almost all the contrast medium entered the subarachnoid space: the second injection was given more slowly and more of the contrast medium may have passed through the proximal hole and spread into the extradural space. In the same way, because the reinforcing dose of local anaesthetic was given very slowly, it may be that only 50 per cent of this dose, that is $5 \mathrm{ml}$, entered the subarachnoid space. Although this may be expected to give an extensive subarachnoid block, 0.5 per cent bupivacaine is slightly hypobaric when injected intrathecally ${ }^{8}$ and as the patient was in a slightly head-down position, the hypobaricity of the solution could explain the limited extent of the block. Indeed, in subarachnoid block a poor correlation has been reported between the volume of hypobaric tetracaine and the level of analgesia: blocks sometimes failed to extend above T10 despite doses up to $15 \mathrm{ml}$ of anaesthetic solution. ${ }^{9}$

\section{SUMMARY}

A case is reported of an uneventful continuous extradural block in spite of unrecognized dural perforation. Although the perforation was recognized later during the block, the dura was probably pierced during the insertion of the catheter and only later the terminal hole came to lie in the subarachnoid space. Consequently both extradural and subarachnoid spread of the injected local anaesthetic occurred, preventing an extensive subarachnoid block.

\section{RÉSUMÉ}

L'auteur rapporte un cas d'analgésie péridurale sans complications cliniques, malgré une perforation non reconnue de la dure-mère. Bien que l'on se soit rendu compte de la perforation tardivement en cours d'intervention, celle-ci est probablement survenue au cours de l'insertion du cathéter. Ce dernier est vraisemblablement venu se placer vis-à-vis l'ouverture dure-méridienne à la suite des doses de rappel d'anesthésique, la solution se distribuant dans les deux espaces (sousdural et péridural), ce qui explique l'absence d'un bloc sous-arachnoiddien total.

\section{REFERENCES}

1. Carr, M.F. \& Hehre, F.W. Complications of continuous lumbar peridural ane sthesia. I. Inadvertent lumbar puncture. Anesth. \& Analg. 41: 349-353 (1962).

2. Molr, D.D. \& Hesson, W.R. Dural puncture by an epidural catheter. Anaesthesia 20: 373-374 (1965).

3. CRAwford, J.S. Lumbar epidural block in labour: a clinical analysis. Brit. J. Anaesth. 44: 66-74 (1972).

4. CRAWfORD, J.S. The strange case of the inadvertent continuous spinal. Brit. J. Anaesth. 46: 82 (1974).

5. REISNER, 1.S. Epidural test solution or spinal fluid? Anesthesiology $44: 451$ (1976).

6. PhILIP, J.H. \& BRown, W.V. Total spinal anes* thesia late in the course of obstetric bupivacaine epidural block. Anesthesiology 44 : 340-341 (1976).

7. HaRtley, M. The strange case of inadvertent spinal. Brit. J. Anaesth. 47: 420 (1975).

8. Davis, H. Specific gravity and density. Anesthesiology 44: 270-271 (1976).

9. Kallos, T. \& SMITH, T.C. Continuous spinal anesthesia with hypobaric tetracaine for hip surgery in lateral decubitus. Anesth. \& Analg. 51: $766-773$ (1972). 